\title{
Comparative study on efficacy and safety of morning dose versus evening dose of levothyroxine in treatment of hypothyroidism: an outpatient department based prospective interventional study
}

\author{
Umakanta Mahapatra ${ }^{1}$, Ram N. Maiti², Bulbul Purkait ${ }^{3}$, Dipan Saha**, Sekhar Mandal ${ }^{2}$
}

\begin{abstract}
${ }^{1}$ Department of Internal Medicine, ${ }^{2}$ Department of Pharmacology, Midnapore Medical College, West Bengal, India ${ }^{3}$ Department of Biochemistry, Purulia Government Medical College, West Bengal, India

${ }^{4}$ Department of Emergency Medicine, Murshidabad Medical College, West Bengal, India
\end{abstract}

Received: 30 July 2020

Accepted: 01 September 2020

*Correspondence:

Dr. Dipan Saha,

Email: drdipans@gmail.com

Copyright: (c) the author(s), publisher and licensee Medip Academy. This is an open-access article distributed under the terms of the Creative Commons Attribution Non-Commercial License, which permits unrestricted non-commercial use, distribution, and reproduction in any medium, provided the original work is properly cited.

\begin{abstract}
Background: One of the common endocrine disorders in India as well as in the world is hypothyroidism. The treatment of choice is giving levothyroxine supplement orally to the patient in an empty stomach mostly in the morning. Often many patients feel uncomfortable or inconvenient to take levothyroxine in the early morning. In those patients changing the administration time of levothyroxine may get necessary to increase the patient compliance.

Methods: Drug naïve patients with primary hypothyroidism, randomly selected and assigned into two groups. Patients in group 1 received levothyroxine in the morning minimum one hour before breakfast and in group 2 levothyroxine was given at least two hours after dinner. Thyroid profile of the subjects was assessed at the baseline and reassessed after 8 and 24 weeks and compared with the baseline values.

Results: After 24 weeks we found significant differences in the thyroid profile of the subjects between two groups. Serum thyroid stimulating hormone (TSH) was found to be $8.70 \pm 3.3$ in the morning group and $7.0 \pm 2.3$ in the evening group. TSH levels in the subjects taking the evening dose got closer to the therapeutic target range earlier than the ones taking the drug in the morning.

Conclusions: Levothyroxine intake at bedtime can be a good alternative to levothyroxine intake in the morning for the patients taking concomitant medications.
\end{abstract}

Keywords: Levothyroxine, Hypothyroidism, Prospective interventional study

\section{INTRODUCTION}

Hypothyroidism results from inadequate production of thyroid hormone and the inadequate action of thyroid hormone in the body. Primary hypothyroidism is the principal cause of hypothyroidism; other causes include central deficiency of thyrotropin releasing hormone $(\mathrm{TRH})$ or thyroid-stimulating hormone (TSH). Iodine deficiency is the commonest cause of hypothyroidism worldwide. ${ }^{1}$ Untreated hypothyroidism often associated with hypertension, dyslipidemia, infertility, cognitive impairment and others. The prevalence increases with age, and is higher in females than in males. Data suggests that in the US nearly 13 million people have undiagnosed hypothyroidism. Studies in the United States, Europe, and Japan have reported the prevalence of hypothyroidism to be between 0.6 and 12 per 1000 in women and between 1.3 and 4.0 per 1000 in men. ${ }^{1,2}$ Hypothyroidism can occur due to primary gland failure or insufficient thyroid gland stimulation by the hypothalamus or pituitary gland. Thyroid gland failure in case of primary hypothyroidism can result from congenital abnormalities, autoimmune destruction, iodine deficiency, and infiltrative diseases. ${ }^{2,3}$ Appropriate laboratory evaluation is critical to establish 
the diagnosis of hypothyroidism. The most important test is a sensitive measurement of TSH level. A TSH measurement should always be used as the primary test to establish the diagnosis of primary hypothyroidism. Additional tests like serum free $\mathrm{T} 4$, free $\mathrm{T} 3$, thyroid autoantibodies antithyroid peroxidase and antithyro globulin auto antibodies may be measured if required. While serum TSH level confirms or excludes all patients with primary hypothyroidism, it will not absolutely reliable in case of central hypothyroidism in which the serum TSH level may be low, normal or mildly elevated. ${ }^{4,5}$ Most patients with hypothyroidism usually require lifelong thyroid hormone therapy. Levothyroxine preparations are manufactured in many different dosages and allow titration of an individual patient's requirements. Adults with hypothyroidism require approximately $1.7 \mu \mathrm{g} / \mathrm{kg}$ of body weight per day for full replacement. ${ }^{6,7}$ Drug interaction of levothyroxine has been well documented and concomitant intake of certain drugs and products like cholestyramine resin, sucralphate, iron sulphate, calcium preparations, aluminum antacids, raloxifene, activated charcoal, various soya products, and food and herbal remedies known to be interfering with levothyroxine absorption. ${ }^{8-10}$ Intake of coffee or tea in early morning is a social habit in our country which may interfere with the absorption of levothyroxine as well. ${ }^{11}$ So although the drug is given in the early morning, at least half an hour before breakfast by most of the treating physicians, many patients find it inconvenient due to their lifestyle, or intake of multiple other drugs which they are regularly consuming for some concomitant illnesses and these groups of patients look for some alternative time for levothyroxine intake. Hence the present study was undertaken to see the efficacy of night time levothyroxine administration compared to the morning dose.

\section{METHODS}

Patients diagnosed with primary hypothyroidism and drug naïve, aged between 18 and 75 years were randomly selected and assigned into two groups. None of the patients used medication known to interfere with levothyroxine absorption, nor were they known to have gastro-intestinal disease. Pregnant and lactating mothers were not included in the study. Patients in group 1 received levothyroxine in the morning minimum one hour before breakfast and in group 2 levothyroxine given at least two hours after dinner. Initial dosage was calculated as $1.6 \mathrm{mcg} / \mathrm{kg}$ body weight, and the closest commercially available dosage, that is, 75/100/125 $\mu \mathrm{g}$ was started. Serum T3, T4, TSH levels of the subjects was measured after 8 weeks and 24 weeks from the baseline. After 8 weeks dose titration was done based upon the thyroid profile of individual subjects and the dose was increased or decreased by $25 \mu \mathrm{g} /$ day. The study was carried out for a period of 24 weeks. Thyroid profile of the subjects was compared with the baseline parameters after 8 as well as 24 weeks. Both intra groups as well as inter group comparative analysis were carried out using paired $t$ and unpaired $t$ test respectively. SPSS verion 21 was used for statistical analysis. The data collected and analyzed is expressed as mean \pm SD.

Serum T3 and T4 levels were expressed in nmol/L, and the TSH level was expressed in $\mathrm{mIU} / 1$.

Biochemical reference range of thyroid hormones which was used for diagnosis of hypothyroidism is serum T4: 59-135 nmol/l in males, 65-138 in females. Serum T3: 1.08-3.14 nmol/l. Serum TSH: 0.4-4.2 mIU/1.

Institutional ethics committee approval obtained prior initiating the study. CTRI registration done at the beginning of the study.

\section{RESULTS}

Total 150 patients were included in this study. Among them 128 patients $(85 \%)$ were female and 22 patients (15\%) were male. Female to male ratio was 5.81:1 (Figure 1). Then we have categorized the subjects into different age groups. Majority of the patients (72) were in the age group of 25-34 years, followed (48) by the age group of 35-45 years. Only 4 patients were from the age group of 45-50 years (Figure 2). Majority of the participants (79) were from the overweight category according to their BMI, followed by obese (37) and normal weight category (32) while only 2 subjects fallen into underweight category (Figure 3). WHO Asia Pacific guideline of body mass index was used in this purpose.

Table 1: Comparison of baseline demographic parameters between two groups.

\begin{tabular}{|llll|}
\hline Parameters & $\begin{array}{l}\text { Group 1 } \\
(\mathbf{n = 7 5 )}\end{array}$ & $\begin{array}{l}\text { Group 2 } \\
(\mathbf{n = 7 5})\end{array}$ & $\begin{array}{l}\text { P } \\
\text { value }\end{array}$ \\
\hline Age (years) & 32.66 & 31.49 & 0.33 \\
\hline Weight $(\mathbf{k g})$ & 60.14 & 61.26 & 0.31 \\
\hline Height $(\mathbf{c m})$ & 157.73 & 160 & 0.05 \\
\hline BMI & 24.20 & 23.87 & 0.33 \\
\hline
\end{tabular}

Table 2: Comparison of biochemical parameters between group 1 and group 2 at baseline.

\begin{tabular}{|llll|}
\hline Parameters & Group 1 & Group 2 & $\begin{array}{l}\text { P value } \\
\text { (t test) }\end{array}$ \\
\hline \multirow{2}{*}{ T3 } & $0.95 \pm$ & $0.90 \pm$ & 0.81 \\
\hline \multirow{2}{*}{ T4 } & 0.23 & 0.87 & 0.11 \\
\hline TSH & $73.63 \pm$ & $76.36 \pm$ & 0.04 \\
\hline
\end{tabular}

The demographic data of both group 1 and 2 were compared at the baseline and the differences in both group was found to be statistically insignificant (Table 1). The mean age in group one was 32.66 years compared to 31.49 years in group 2. In group 1 mean BMI was found to be 24.20 , in group 2 it was 23.87 . 
We compared the biochemical parameters between the two groups, beginning from the baseline to the 24th week. At the baseline the mean TSH was $14.63 \pm 5.41$ and 13.44 \pm 5.09 in group 1 and group 2 respectively. The mean serum T4 was 77.2011 .28 was in the group 1 and $76.36 \pm 9.04$ was in the group 2 at the baseline (Table 2). These results were again obtained and compared after 8 weeks. It was evident that the serum TSH and T4 significantly changed from the baseline values (Table 3 ). It indicated that the group 2 might have better control of the disease after 8 weeks as the serum TSH value was lowered more in group 2 compared to group 1 after 8 weeks $(p=0.025)$. The dose of the drug was adjusted after 8 weeks, and we found no significant difference in the mean dose between two groups (Table 7). After 24 weeks the parameters were again compared between the two groups (Table 4).

Table 3: Comparison of biochemical parameters between group 1 and group 2 after 8 weeks.

\begin{tabular}{|llll|}
\hline Parameters & $\begin{array}{l}\text { Group 1 } \\
(\mathbf{n = 7 5 )}\end{array}$ & $\begin{array}{l}\text { Group 2 } \\
(\mathbf{n}=75)\end{array}$ & $\begin{array}{l}\text { P value } \\
(\mathbf{t} \text { test })\end{array}$ \\
\hline T3 & $1.08 \pm 0.95$ & $0.91 \pm 0.092$ & 0.117 \\
\hline T4 & $77.20 \pm 11.28$ & $83.89 \pm 7.91$ & $<0.001$ \\
\hline TSH & $11.04 \pm 3.75$ & $9.81 \pm 2.86$ & 0.025 \\
\hline
\end{tabular}

We found significant differences in the thyroid profile of the subjects between the two groups. Where serum TSH was found to be $8.70 \pm 3.3$ in the group 1 and $7.0 \pm 2.3$ in the group 2, the serum T4 was $89.58 \pm 8.06$ in the group 2 compared to the value of $78.34 \pm 13.19$ in the group 1 .

Table 4: Comparison of biochemical parameters between group 1 and group 2 after 8 weeks.

\begin{tabular}{|llll|}
\hline Parameters & $\begin{array}{l}\text { Group 1 } \\
(\mathbf{n = 7 5})\end{array}$ & $\begin{array}{l}\text { Group 2 } \\
(\mathbf{n = 7 5})\end{array}$ & $\begin{array}{l}\text { P value } \\
\text { (t test) }\end{array}$ \\
\hline T3 & $0.99 \pm 0.14$ & $0.94 \pm 0.10$ & 0.014 \\
\hline T4 & $78.34 \pm 13.19$ & $89.5 \pm 8.06$ & $<0.001$ \\
\hline TSH & $8.70 \pm 3.3$ & $7.0 \pm 2.3$ & $<0.001$ \\
\hline
\end{tabular}

If we compare the biochemical data of those two individual groups from the baseline through to the 24 week, it shows that the serum TSH became 11.04 from 14.62 in the group 1 at the end of 8 weeks (Table 5), on the other hand it was found to be 9.81 in group 2 after 8 weeks, which had a value of 13.44 at the baseline. So we can say both group showed some significant changes in serum TSH after 8 weeks of study, but it was clearly evident that serum TSH value in group 2 was closer to target range than group 1 .

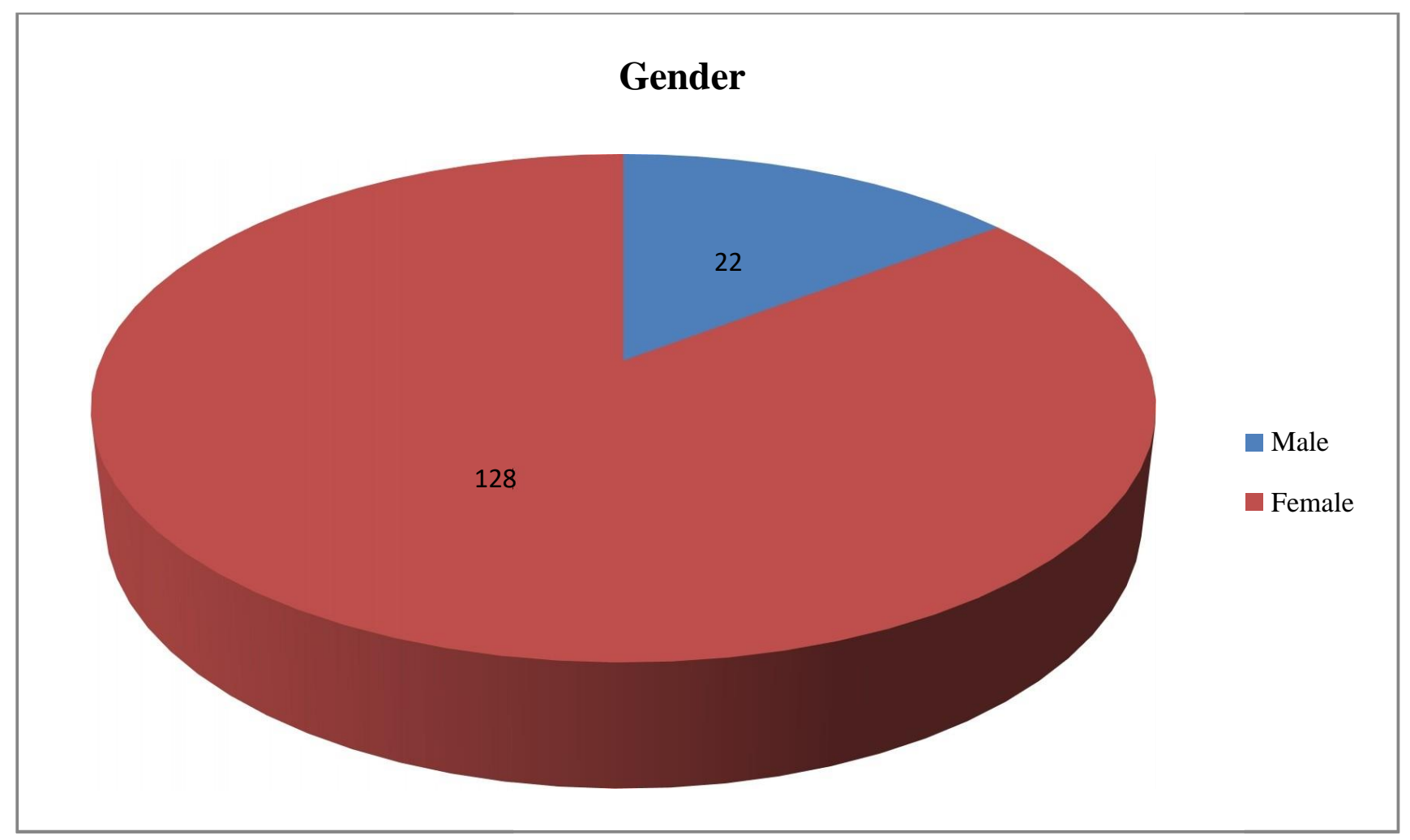

Figure 1: Gender wise distribution. 


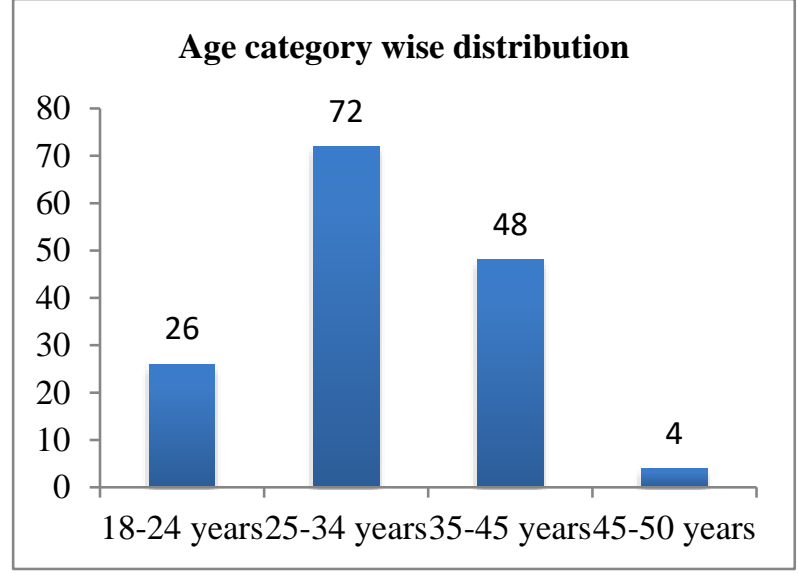

Figure 2: Age category wise distribution

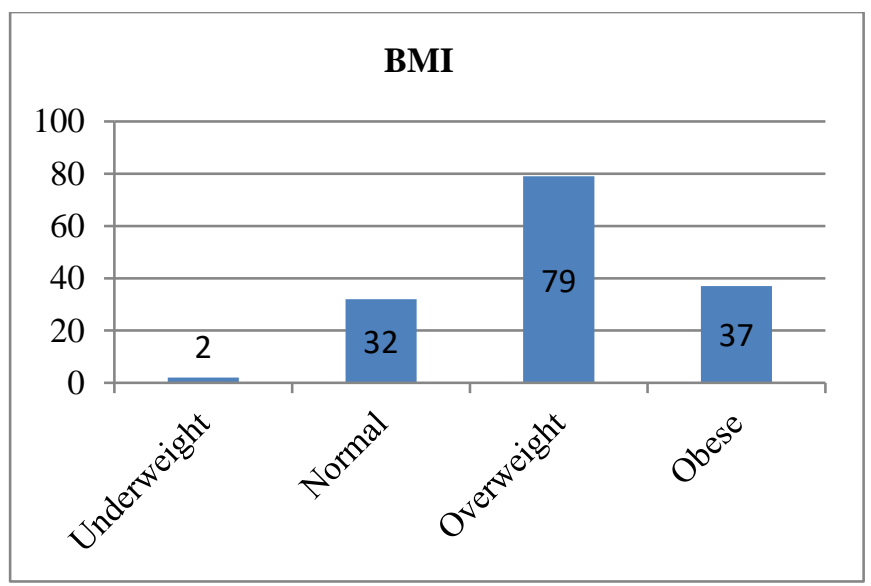

Figure 3: BMI category wise distribution.

Table 5: Comparison of parameter between baseline visit and 1st follow up in two individual groups.

\begin{tabular}{|lllclcc|}
\hline Parameters & \multicolumn{3}{c}{ Group 1 } & & & \multicolumn{2}{c}{ Group 2 } \\
& Baseline & $\mathbf{1}^{\text {st }}$ follow-up & P value & Baseline & 1 $^{\text {st }}$ follow-up & P value \\
\hline T3 & $0.9539 \pm 0.23$ & $1.0865 \pm 0.95$ & 0.228 & $0.9031 \pm 0.8$ & $0.9123 \pm 0.92$ & 0.406 \\
\hline T4 & $73.6333 \pm 11.62$ & $77.2000 \pm 11.28$ & $<0.001$ & $76.3600 \pm 9.04$ & $83.8933 \pm 7.91$ & $<0.001$ \\
\hline TSH & $14.6287 \pm 5.41$ & $11.04 \pm 3.75$ & $<0.001$ & $13.44 \pm 5.09$ & $9.81 \pm 2.86$ & $<0.001$ \\
\hline
\end{tabular}

Table 6: Comparison of parameter between baseline visit and 2nd follow up in two individual groups.

\begin{tabular}{|lllllll|}
\hline Parameters & Group 1 & Group 2 & & & 2 \\
& Baseline & $\mathbf{2}^{\text {nd }}$ follow-up & P value & Baseline & 2 $^{\text {nd }}$ follow-up & P value \\
\hline T3 & $0.9539 \pm 0.234$ & $0.9928 \pm 0.14$ & 0.130 & $0.9539 \pm 0.234$ & $0.9413 \pm 0.10$ & 0.004 \\
\hline T4 & $73.6333 \pm 11.62$ & $78.34 \pm 13.19$ & 0.001 & $73.6333 \pm 11.62$ & $89.58 \pm 8.06$ & $<0.001$ \\
\hline TSH & $14.6287 \pm 5.41$ & $8.69 \pm 3.30$ & $<0.001$ & $14.6287 \pm 5.41$ & $7.00 \pm 2.29$ & $<0.001$ \\
\hline
\end{tabular}

Similarly, if we go through the data of the two individual groups after 24 weeks we can see some significant changes took place in the level of serum TSH as well as T4 levels from the baseline values (Table 6). The serum T4 became $78.34 \mathrm{nmol} / \mathrm{l}$ after 24 weeks in group 1 whereas it reached the level of $89.58 \mathrm{nmol} / \mathrm{l}$ in group 2 . Serum TSH became 8.69 in group 1 after 24 weeks and it got as low as 7.00 in group 2 after same period of time. It was seen that after 24 weeks that subjects of both group 1 and 2 were responding to levothyroxine therapy, but overall the response of group 2 in terms of thyroid profile was better at the end of the study.

Table 7: Comparison of levothyroxine dosage between group 1 and group 2.

\begin{tabular}{|llll|}
\hline $\begin{array}{l}\text { Dose of } \\
\text { LT4 }\end{array}$ & $\begin{array}{l}\text { Group 1 } \\
(\mathbf{n}=75)\end{array}$ & $\begin{array}{l}\text { Group 2 } \\
(\mathbf{n}=75)\end{array}$ & $\begin{array}{l}\text { P value } \\
(\mathbf{t} \text { test })\end{array}$ \\
\hline $\mathbf{1}^{\text {st }}$ visit & $84.83 \pm 23.72$ & $80.83 \pm 63$ & 0.303 \\
\hline $\mathbf{2}^{\text {nd }}$ visit & $80.54 \pm 22.73$ & $79.84 \pm 22.87$ & 0.851 \\
\hline $\mathbf{3}^{\text {rd }}$ visit & $76.74 \pm 22.95$ & $76.39 \pm 24.13$ & 0.927 \\
\hline
\end{tabular}

Comparison of mean doses of levothyroxine between two groups beginning from the baseline to 1 st and 2 nd follow up was done. Dosage requirement in both groups were not significantly different throughout the study (Table 7). No adverse drug reactions were reported till the end of the study.

\section{DISCUSSION}

Prevalence of hypothyroidism is high worldwide, it's even higher among female population, affecting 0.6 to 12 out of every 1000 women across Europe, Japan and the U.S. ${ }^{12}$ In our study we came across similar result, as the demographic data indicates the incidence of hypothyroidism was higher among female than male (female to male ratio 5.81:1). The TICO study had similar findings, where among 77 participants 64 were female patients of primary hypothyroidism. ${ }^{13}$ One of the cardinal feature of hypothyroidism is weight gain. ${ }^{4}$ In our study most of the subjects were from the overweight category, followed by the obese category.

During diagnosis and recruitment, we found 25-34 years of age group was commonest among all, followed by 35 45 years. In some studies, the mean age of the subjects 
found to be 45.4 years with a standard deviation of 13.7 years, indicating towards similar findings. ${ }^{12}$

Upon diagnosis oral levothyroxine was initiated in all the subjects across two groups. Although the dosage of the drug required have shown similar results in both the groups, but subjects in group 2 showed earlier reduction in serum TSH value, and faster progression towards achieving euthyroid status compared to group 1 . If we see the results of the study conducted by Rajput et al at a teaching institute of northern India in 2011 it showed both the morning and evening group showed good response to the treatment but the number of the patients achieving euthyroid state were better in the evening group, which is comparable to the results of our study. ${ }^{8}$ In contrast a study conducted by Huynh et al where they showed levothyroxine administration is commonly associated with more variable serum TSH concentration, and to achieve the target serum TSH level in an individual, ingestion of levothyroxine before breakfast can be the best regimen among all. ${ }^{14}$ Bolk et al conducted similar study where they recruited 90 subjects and compared the effects of morning vs evening dose of levothyroxine sodium. ${ }^{15}$ They showed that levothyroxine taken at bedtime significantly improved thyroid hormone levels, but quality of life parameters and plasma lipids showed no significant change as compared to morning intake. Similarly in our study subjects in group 2 better thyroid hormone levels compared to group 1. TSH levels in the subjects taking the evening dose got closer to the therapeutic target range earlier than the ones taking the drug in the morning. These findings suggest that bedtime administration of levothyroxine not inferior to morning administration, as the dosage required getting closer to the therapeutic target level of TSH is not significantly different in the participating groups in our study.

\section{CONCLUSION}

Based on the results of our study, we can say that evening dose is as efficacious as morning dose in improvement of thyroid profile, improvement of clinical signs and symptoms. Clinicians should inform patients with hypothyroidism that levothyroxine intake at bedtime can be a good alternative to levothyroxine intake in the morning, especially in those taking concomitant medications in the morning which can interfere with the absorption of levothyroxine.

\section{ACKNOWLEDGEMENTS}

Writing assistance and general support was given by Mrs. Sharmistha Ghosh.

Funding: No funding sources Conflic tof interest: None declared

Ethical approval: The study was approved by the Institutional Ethics Committee

\section{REFERENCES}

1. Ala S, Akha O, Kashi Z, Asgari H, Bahar A, Sasanpour N. Dose administration time from before breakfast to before dinner affect thyroid hormone levels?. Casp J Inter Med. 2015;6(3):134.

2. Gaitonde Y, Rowley D, Sweeny B. Hypothyroidism: an update. American Family Physicians. 2012;86(3):244-51

3. Singer A. Tyroiditis. Acute, subacute, and chronic. Med Clin North Am. 1991;75(1):61-77

4. Ladenson W, Singer A, Ain B, Bagchi N, Bigos T, Levy G, et al. American Thyroid Association guidelines for detection of thyroid dysfunction. Arch Intern Med. 2000;160(11):1573-5.

5. Baskin J, Cobin H, Duick S, Gharib H, Guttler B, Kaplan M, et al. American association of clinical endocrinologists medical Guidelines for clinical practice for the evaluation and treatment of hyperthyroidism and hypothyroidism: AACE Thyroid Task Force. Endocr Pract. 2002;8(6):457-69.

6. Singer A, Cooper S, Levy G, Ladenson W, Braverman E, Daniels G et al. Treatment guidelines for patients with hyperthyroidism and hypothyroidism. J Ame Med Asso. 1995;273(10): 808-12.

7. American Association of Clinical Endocrinologists. AACE, TES, and ATA joint position statement on the use and interchangeability of thyroxine products. Available at. http://www.aace.com/files/AACE-TESATA-Thyroxine Products.pdf. Accessed on 02 July 2020.

8. Rajput R, Chatterjee S, Rajput M. Can Levothyroxine Be Taken as Evening Dose? Comparative Evaluation of Morning versus Evening Dose of Levothyroxine in Treatment of Hypothyroidism. J Thyroid Res. 201;2011:505239.

9. Sherman S, Tielens E, and Ladenson P. Sucralfate causes malabsorption of L- thyroxine. Ame J Med. 1994;96(6):531-5.

10. Singh N, Singh N, Hershman M. Effect of Calcium Carbonate on the Absorption of Levothyroxine. J Ame Med Asso. 2000;283(21):2822-5.

11. Benvenga S, Bartolone L, Pappalardo A, Russo A, Lapa D, Giorgianni G, et al. Altered intestinal absorption of L-thyroxine caused by coffee. Thyro. 2008;18(3):293-301.

12. Roelfsema F, Pereira M, Adriaanse R, et al. Thyrotropin secretion in mild and severe primary hypothyroidism is distinguished by amplified burst mass and Basal secretion with increased spikiness and approximate entropy. J Clin Endocrinol Metab 2010;95:928-34.

13. Kim H, Kim W, Ahn Y, Choi S, Won H, Choi Y, et al. Effect of seasonal changes on the transition between subclinical hypothyroid and euthyroid status. J Clin Endocrinol Metab. 2013;98(8):3420-9.

14. Huynh T, Nayak B, Loh J, Soldin S, Jonklaas J. Timing of levothyroxine administration affects serum 
thyrotropin concentration. J Clin Endocrinol Metab. 2009;94(10):3905-12.

15. Bolk N, Visser J, Nijman J, Jongste J, Tijssen G, Berghout A. Effects of evening vs morning levothyroxine intake. Arch Inter Med. 2010;170:1996-2003.
Cite this article as: Saha D, Mahapatra U, Maiti R, Purkait B, Mandal S. Comparative study on efficacy and safety of morning dose versus evening dose of levothyroxine in treatment of hypothyroidism: an outpatient department based prospective interventional study. Int J Basic Clin Pharmacol 2020;9:1554-9. 